\title{
High pressure jet injection of viscous solutions for endoscopic submucosal dissection (ESD): first clinical experience
}

Authors

Institutions
Mathieu Pioche ${ }^{1,2,3}$, Vincent Lépilliez ${ }^{1,4}$, Pierre Déprez ${ }^{5}$, Marc Giovannini ${ }^{6}$, Fabrice Caillol ${ }^{6}$, Hubert Piessevaux ${ }^{5}$, Jérôme Rivory ${ }^{1}$, Olivier Guillaud ${ }^{1}$, Mihai Ciocîrlan ${ }^{1,7}$, Damien Salmon ${ }^{8}$, Isabelle Lienhart ${ }^{1}$, Cyril Lafon ${ }^{3}$, Jean-Christophe Saurin ${ }^{1}$, Thierry Ponchon ${ }^{1,3}$

Institutions are listed at the end of article. submitted

6. November 2014 accepted after revision

24. February 2015

\section{Bibliography}

DOI http://dx.doi.org/

10.1055/s-0034-1391902

Published online: 14.4.2015

Endosc Int Open 2015; 03:

E368-E372

(c) Georg Thieme Verlag KG

Stuttgart · New York

E-ISSN 2196-9736

\section{Corresponding author}

\section{Mathieu Pioche, MD}

Endoscopy unit

Digestive Disease Department

H Pavillon - Edouard Herriot

Hospital

69437 Lyon Cedex

France

Fax: +33-4-72110147

mathieu.pioche@chu-lyon.fr
Background: Long lasting elevation is a key factor during endoscopic submucosal dissection (ESD) and can be obtained by water jet injection of saline solution or by viscous macromolecular solutions. In a previous animal study, we assessed the Nestis Enki II system to combine jet injection and viscous solutions. In the present work, we used this combination in humans in different sites of the digestive tract.

Methods: We retrospectively report all of the consecutive ESD procedures performed with jet injection of viscous solutions in four centers. Information was collected about the lesion, the procedure, the histological result, and the outcomes for the patient.

Results: In total, 45 resections were completed by six operators: five experts and one beginner with only one previous experience in human ESD. Lesions were located in the esophagus (10), the

\section{Introduction}

\section{$\nabla$}

In expert hands, endoscopic submucosal dissection (ESD) is the method of choice to treat superficial neoplastic lesions of the digestive tract larger than $20 \mathrm{~mm}$ as it allows "en bloc" resection $[1,2]$. Nonetheless, it carries a high perforation rate and may be a lengthy procedure with numerous changes of devices for elevation and dissection. Use of a water jet with a bifunctional (injection and cutting) catheter saves time with a significant reduction in perforation risk $[3,4]$. In addition, injection of macromolecular solutions such as a glycerol mixture or hyaluronic acid induces long lasting elevation to perform ESD in a stable situation [5]. Water jet injection of macromolecular solutions theoretically combines the advantages of both water jet and macromolecules but, so far, available systems have not been able to inject viscous solutions. The Nestis water jet allows pulsed injection of macromolecules, even with the endoscope retroflexed. This system has stomach (11), the duodenum (1), the colon (1) and the rectum (22). Average maximal lesion diameter was $4.8 \mathrm{~cm}$ (SD 2.4, range $2-11 \mathrm{~cm}$ ), average lesion surface area was $19.8 \mathrm{~cm}^{2}$ (SD 17.7, range $2.2-72 \mathrm{~cm}^{2}$ ), and average duration of procedure was $79.9 \mathrm{~min}$ (SD $50.3 \mathrm{~min}$, range 19-225 min). ESD could be conducted while the endoscope was retroflexed at its maximum in 26 cases. Four adverse events were observed: two diminutive perforations and two delayed bleeding occurrences treated conservatively. The R0 resection rate was $91.1 \%$. The catheter was obstructed in six occurrences of bleeding.

Conclusion: Endoscopic submucosal dissection using high pressure injection of viscous macromolecular solutions is safe and effective in different parts of the digestive tract. It does not impede working with the endoscope in the maximal retroflexed position.

shown its ability to inject hyaluronate, glycerol mixture, or hydroxyethyl starch (HES) in pig stomach [6]. In pig colon, it has demonstrated its superiority versus conventional ESD (needle and knife) in terms of safety issues [3]. In isolated pig stomach, ESD using hyaluronate was quicker than saline when both were injected by the water jet. We now report retrospectively the first clinical cases using macromolecular jet injection in different sites of the digestive tract in four expert centers in France and Belgium between January 2013 and January 2014.

\section{Material and methods \\ $\nabla$}

Water jet system and bifunctional catheter The water jet system used in this study (Nestis ${ }^{\circledR}$ Enki II ${ }^{\circledR}$, Lyon, France) is not a pump like other available water jets such as ERBE Jet ${ }^{\circledR}\left(\mathrm{ERBE}^{\circledR}\right.$, Tübingen, Germany), but it comprises a high pressure chamber ( $\bullet$ Fig. $\mathbf{1}$ a) that can accommodate 


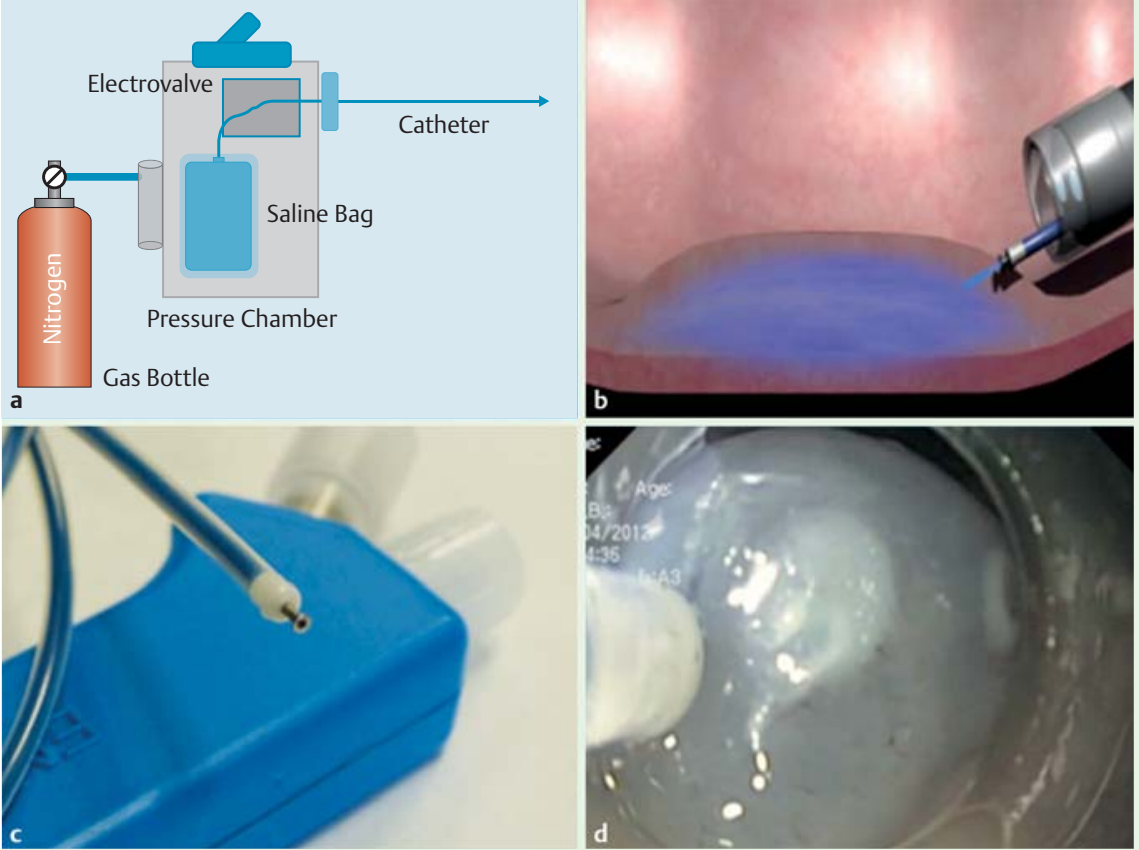

Fig. 1 Nestis Enki II ${ }^{\circledR}$ system: a operating principles; $\mathbf{b}$ schematic injection in the submucosal tissue, $\mathbf{c}$ catheter; $\mathbf{d}$ endoscopic view of the catheter during an endoscopic submucosal dissection (ESD) procedure.

and compress plastic bags of saline or viscous solutions. The pressure in the chamber is obtained with medical nitrogen and can be set by the operator between 2 and 25 bars using a touchscreen. A flexible tube is connected to the plastic bag in the chamber. This tube passes through an electric clamp controlled by a foot pedal before exiting the pressure chamber and is connected to the cutting knife with a standard luer-lock connection ( $\bullet$ Fig.1 b). This system allows a pulsed injection that theoretically can improve mucosal elevation by pulsing thanks to a hammer effect. The Nestis ${ }^{\circledR}$ knife is a bifunctional catheter (injection through the catheter and cutting with the electrode that is connected to an electrosurgical generator) with a $2.3 \mathrm{~mm}$ external diameter sheath covering a retractable metal electrode $1.8 \mathrm{~mm}$ long with a distal plate of $1.2 \mathrm{~mm}$ diameter. The injection hole is $200 \mu \mathrm{m}$ wide and is central to the metal electrode ( $\bullet$ Fig. 1 c). In contrast with Flushknife BT (DK2618JN, FUJIFILM ${ }^{\circledR}$, Saitama, Japan), the liquid is injected under higher pressure at the distal part of the catheter in the center of the plate and not around the electrode. In contrast with other water jets available, the Nestis system is able to inject macromolecular viscous solutions through a very soft catheter ( $\bullet$ Fig.1d). Suction is thus preserved during the procedure even on endoscopes with standard working channels and its flexibility allows working in a retroflexed position with smooth movements. The pressure used during the whole study was 12 bars since this level was demonstrated to be effective to obtain good elevation without any perforation during earlier studies on living animals [6]. The injection is controlled by the operator using a foot pedal and can be precisely chosen by the physician. The activation and termination of the injection occur immediately after the action on the pedal so the control of the mucosal cushion is precisely determined by the operator himself and avoids misunderstandings with the assistant. The system also allows a precise volume to be injected, controlled by the operator on the screen of the machine, but usually all of the operators prefer to control the mucosal cushion using the foot pedal exactly as we do, whereas the assistant usually injects with the needle.

\section{Methods}

We retrospectively included all of the consecutive patients who underwent an ESD procedure between January 2013 and January 2014 using the Nestis ${ }^{\circledR}$ water jet system and with injection of a macromolecular solution. The macromolecular solutions used were: hydroxyethyl starch 130/0.4 (HES, Voluven ${ }^{\circledR}$, Fresenius $\mathrm{Kabi}^{\circledR}$, France), a mixture of glycerol (glycerol $10 \%$, fructose $5 \%$, and normal saline solution, produced by Edouard Herriot pharmacy, Lyon), carboxymethyl cellulose solution, and Geloplasma ${ }^{\circledR}$ (sodium lactate solution). In French centers, a glycerol mixture (produced by Edouard Herriot hospital pharmacy) was the first choice if available, and otherwise, we used HES. Hyaluronate was not used in clinical practice for cost reasons.

\section{ESD procedures}

The choice of endoscope depended on the operator and the location of the lesion but was always upper gastrointestinal scopes for cases involving the rectum, esophagus, or stomach. All interventions were performed with a distal transparent hood attached to the tip of the scope ( $4 \mathrm{~mm}$ length with a $3 \mathrm{~mm}$ hole, D201-11304, Olympus ${ }^{\circledR}$, Tokyo, Japan). The lateral margins of the targeted neoplasia were determined by white light, narrowband imaging, and/or chromoendoscopy (using indigo carmine spray for stomach and colon, acetic acid for Barrett's lesion, and iodine for squamous cell lesions). The tip of the Nestis ${ }^{\circledR}$ knife was then used for marking if needed. Submucosal injection was performed using the Nestis ${ }^{\circledR}$ knife: in the stomach, Barrett's esophagus, and colon, injection was possible directly by applying the catheter against the mucosa, while in squamous cell esophageal mucosa, injection was done through a previous coagulation point. Submucosal injection of macromolecular solution colored with indigo carmine blue was accomplished without a needle using the Nestis ${ }^{\circledR}$ knife under 12 bars of pressure to obtain a clearly visible mucosal elevation. We used the ERBE ${ }^{\circledR}$ VIO 200D (ERBE ${ }^{\circledR}$, Tübingen, Germany) electrosurgical unit with the following settings:

- Soft coagulation, effect 4,50W, for marking and hemostasis.

- Endocut mode I, effect 4, for circumferential incision.

- Swift coagulation, effect 3,40W, for dissection. 
Visible vessels were coagulated with the Nestis ${ }^{\circledR}$ knife, and larger vessels were coagulated with diathermic forceps. Hemoclips were only used in the case of failure of these techniques. Circumferential cutting was performed totally or partially before beginning ESD, and the tunnel method [7] could be used for esophageal dissection. For dissection, submucosal injection was performed with the same technique as for circumferential cutting. There was no limitation concerning the number and registered volume of injections during the procedure. After endoscopic removal of the specimen, the resected area was investigated for residual superficial vessels, which were then coagulated with the Nestis ${ }^{\circledR}$ knife or, if necessary, with coagulation forceps. In the different centers involved in this study, the same strategy using one needle type knife and a diathermic forceps for hemostasis is common including when using other devices such as the Dualknife ${ }^{\circledR}$ (Olympus ${ }^{\circledR}$, Tokyo, Japan) or FlushKnife ${ }^{\circledR}$ (Fujinon ${ }^{\circledR}$, Tokyo, Japan). The choice of the diathermic forceps (Olympus ${ }^{\circledR}$, Tokyo, Japan) to replace the Coagrasper ${ }^{\circledR}$ (Olympus, Tokyo, Japan) is justified for the cost effectiveness of the procedure in our countries where a specific reimbursement for ESD does not exist.

The duration of the procedure corresponded to the period between the beginning of marking and the end of the procedure including prophylactic hemostasis after lesion removal. Specimen size was measured at the end of the procedure on the lesion stretched on cork, and was defined by its two larger diameters and its surface area using the formula for an ellipse: Area $\left(\mathrm{cm}^{2}\right)=$ $($ small diameter $(\mathrm{cm}) / 2) \times($ large diameter $(\mathrm{cm}) / 2) \times \pi$ as used in previous reports [6]. Dissection speed was defined as follows: Speed $\left(\mathrm{cm}^{2} / \mathrm{min}\right)=$ area $\left(\mathrm{cm}^{2}\right) /$ duration $(\mathrm{min})$.

\section{Adverse events}

A perforation was a complete muscular layer opening, while an incomplete muscle tear was defined as damage to the inner circular muscle layer. Perforation was immediate when diagnosed during the procedure or delayed when discovered later after recovery. Delayed perforation was diagnosed by a computed tomography (CT) scan required by the patient's symptoms (pain, fever, abdominal guarding).

Significant bleeding was defined as a hemoglobin level drop of more than $2 \mathrm{~g} / \mathrm{dL}$ or ongoing clinically overt bleeding that required endoscopic hemostasis and/or blood transfusion.

\section{Preparation and pathology evaluation of the resected specimen}

Each resected specimen was gently stretched and fixed on cork with needles immediately after lesion removal. Completeness of the specimen including identification of the marking dots was assessed. The specimen was stored in $4 \%$ neutral buffered formalin for subsequent pathological evaluation. Separate expert pathologists in each of the four centers performed pathology examination. The specimens were sectioned completely into $1.5-\mathrm{mm}$ slices for evaluation of type and grade of neoplasia, vertical depth of tumor invasion, and completeness of vertical (VM0) and horizontal resection (HMO) of neoplasia or with tumor-infiltrated margins (R1), laterally (HM1), or deeply (VM1), and undetermined margins due to coagulation artifacts or piecemeal resection (Rx, HMx, VMx). In addition, permeation of lymphatic or blood vessels was investigated.

"En bloc" resection was defined macroscopically as a one piece complete resection of the superficial epithelial neoplastic lesion, thus obtaining a single specimen for subsequent histological a-
Table 1 Results for the 45 procedures.

\begin{tabular}{|l|c|}
\hline Number of procedures, $\mathrm{n}$ & 45 \\
\hline Esophagus, $\mathrm{n}$ & 10 \\
\hline Stomach, $\mathrm{n}$ & 11 \\
\hline Duodenum, $\mathrm{n}$ & 1 \\
\hline Ascending colon, $\mathrm{n}$ & 1 \\
\hline Rectum, $\mathrm{n}$ & 22 \\
\hline R0 resection & \\
\hline All, $\mathrm{n}(\%)$ & $41(91.1)$ \\
\hline Esophagus, $\mathrm{n}(\%)$ & $9(90)$ \\
\hline Stomach, $\mathrm{n}(\%)$ & $10(90.9)$ \\
\hline Duodenum, $\mathrm{n}(\%)$ & $1(100)$ \\
\hline Ascending colon, $\mathrm{n}(\%)$ & $1(100)$ \\
\hline Rectum, $\mathrm{n}(\%)$ & $20(90.9)$ \\
\hline Maximal diameter, mean (SD), cm & $4.8(2.4)$ \\
\hline Duration, mean (SD), min & $79.9(50.3)$ \\
\hline Area, mean (SD), cm² & $19.8(17.7)$ \\
\hline Speed, mean (SD), cm ${ }^{2} /$ min & $0.27(0.18)$ \\
\hline Length of stay, mean (SD), days & $2.8(1.3)$ \\
\hline Bubble around rectum, $\mathrm{n}(\%)$ & $2(4.4)$ \\
\hline Delayed bleeding occurrences, $\mathrm{n}(\%)$ & $2(4.4)$ \\
\hline Intraoperative perforation, $\mathrm{n}$ & 0 \\
\hline Injection issues, $\mathrm{n}(\%)$ & $6(13.3)$ \\
\hline
\end{tabular}

nalysis. Piecemeal resection was defined as removal of the lesion in at least two separate pieces.

R0 resection was defined as an "en bloc" resected lesion with tumor-free lateral and in-depth resection margins at histological examination. At histological examination, lesions with non-assessable resection borders were termed Rx, whereas lesions with resection margins in contact with pathological tissue were termed R1.If the lesion could not be completely resected, the resection was termed R2 and considered to be an ESD procedure failure [8].

Curative resection was defined as an R0 resection of a well differentiated neoplastic lesion without vascular or lymphatic emboli.

\section{Statistics}

Data were collected prospectively using the same report form in all of the four centers and then analyzed using descriptive statistics (mean and standard deviation as well as mean and range).

\section{Results ( 0 Table 1 )}

$\nabla$

\section{Procedures (example, 0 Fig. 2)}

In total, 45 patients underwent ESD (22 female, mean age 65.3 years (range 36-92)). Six endoscopists performed these procedures (five experienced and one beginner in human ESD). All procedures in the rectum and two in the gastric cardia were mainly performed in retroflexion with no loss of jet power. Among esophageal procedures, six were resected using the tunnel technique in two centers in Lyon and the others were performed by the standard technique without submucosal tunneling.

Among the 45 procedures, 44 were endoscopically complete with marking dots and one seemed complete but without macroscopic margins. All resections were en bloc using only the Nestis ${ }^{\circledR}$ knife in 40 cases, and other devices were used in five cases: IT knife $2^{\circledR}$ (Olympus $^{\circledR}$, Tokyo, Japan) in one stomach case in Mermoz hospi- 


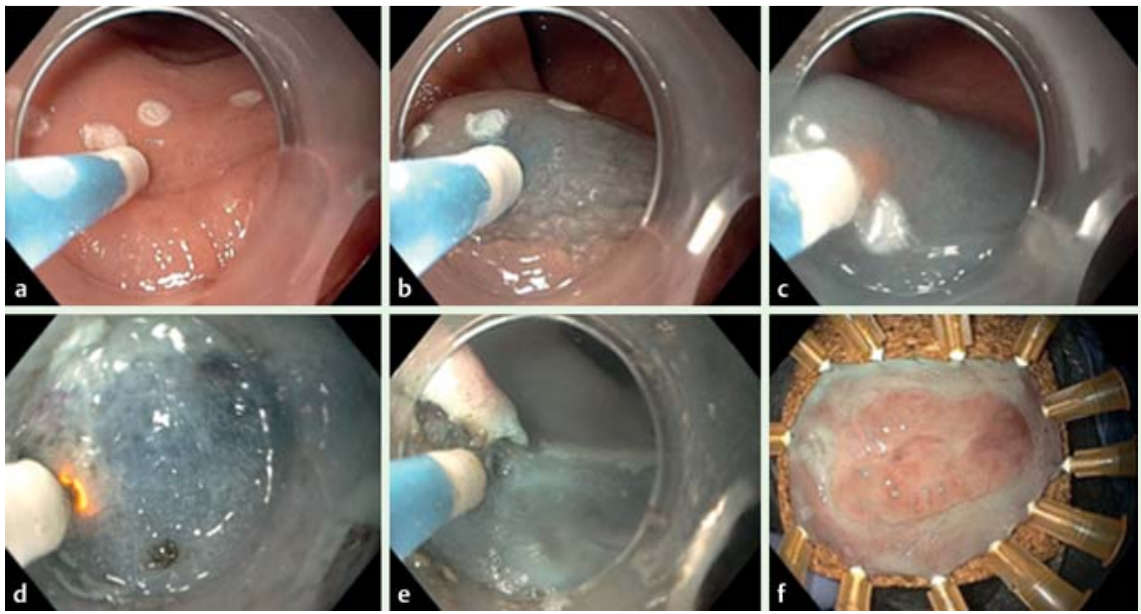

Fig.2 Images of a procedure using Nestis ${ }^{\circledR}$ for a lateral spreading tumor (nongranular type) (LSTNG) of the rectum: a after marking, before first injection; $\mathbf{b}$ first injection through the mucosa; $\mathbf{c}$ first cutting; $\mathbf{d}$ submucosal dissection; e end of dissection; $\mathbf{f}$ piece stretching.

tal, and the Dual knife ${ }^{\circledR}$ and IT knife $2^{\circledR}$ in four cases in Louvain. Diathermy forceps (Hot biopsy forceps ${ }^{\circledR}$, Olympus $^{\circledR}$, Tokyo, Japan) were always used $(n=45)$ for coagulation of large vessels, in the case of bleeding during the procedure, or to perform the prophylactic hemostasis after resection.

The procedures were performed by injecting different macromolecular solutions: HES $(n=25)$, glycerol mixture $(n=14)$, Geloplasma $^{\circledR}(n=5)$, or carboxymethyl cellulose solution $(n=1)$. Injection was always possible during the procedures apart from six cases owing to a catheter obstruction. This occurred in bleeding situations after a mean time of $58 \mathrm{~min}$ (range $30-90 \mathrm{~min}$ ) due to carbonization at the tip of the device. To finish the procedure in these six cases, other devices were used in four cases (Dual Knife ${ }^{\circledR}$ in one case, Dual Knife + IT knife ${ }^{\circledR}$ in two cases, IT Knife $2^{\circledR}$ in one case) and a new Nestis ${ }^{\circledR}$ catheter was used in the other two cases. In four cases, installation of the cartridge in the electric clamp was incorrect and damaged the tube before the beginning of the procedure. Nevertheless, injection was possible after cartridge replacement.

Bubbles appeared in the working field during the procedure while using carboxymethyl cellulose solution $(\mathrm{n}=1$, a significant amount of foam) and Geloplasma ${ }^{\circledR}(n=5$, a few bubbles) but they were not reported with the glycerol mixture $(n=14)$ or HES $(n=$ 25).

The average time for the procedure was $79.9 \mathrm{~min}$ (SD 50.3, range $19-225 \mathrm{~min})$. The average dissection speed was $0.27 \mathrm{~cm}^{2} / \mathrm{min}$ (SD 0.18 , range $0.06-0.7 \mathrm{~cm}^{2} / \mathrm{min}$ ).

\section{Lesions}

Among the 45 specimens, the resections involved:

- 22 lateral spreading tumors of the rectum (LST) (five low grade dysplasia (LGD), nine high grade dysplasia (HGD), six mucosal carcinoma, one submucosal carcinoma with less than $1000 \mu \mathrm{m}$ invaded ( $\operatorname{sm} 1$ ), one submucosal carcinoma with less than $1000 \mu \mathrm{m}$ invaded ( $\mathrm{sm} 1$ ) but with lymphatic emboli),

- 11 gastric lesions (three HGD, five mucosal carcinoma, two fibroid inflammatory polyps, one hyperplastic polyp),

- 10 esophageal lesions (two mucosal squamous cell carcinoma [SCC], eight lesions on Barrett's esophagus [BE] [six mucosal carcinoma (one with ring cells), one HGD and one LGD]),

- 1 of the ascending colon (sessile serrated lesion HGD),

- 1 of the second duodenum (LGD) in Belgium.

The average maximal lesion diameter was $4.8 \mathrm{~cm}$ (SD 2.4, range $2-11 \mathrm{~cm}$ ) and the average area was $19.8 \mathrm{~cm}^{2}$ (SD 17.7, range $\left.2.2-72 \mathrm{~cm}^{2}\right)$. In total, $41(91.1 \%)$ of the 45 procedures resulted in $\mathrm{R} 0$ resection with safe margins in depth (VM0) and laterally (HM0). From the four remaining procedures, all four were R1 on the lateral margin: the first two procedures by the unskilled operator (focally for one rectal LST, on $5 \mathrm{~mm}$ for the other rectal LST), one fibroid inflammatory polyp without margin, one esophageal adenocarcinoma with HGD margins.

Among the 45 lesions, 40 (88.9\%) of the 41 R0 resections were considered curative after pathology analysis since one lesion presented lymphatic emboli.

\section{Adverse events}

No perforation occurred during the procedures. Four adverse events were observed: two delayed diminutive perforations (4.4\%) and two delayed occurrences of bleeding. Concerning the diminutive perforations, CT scans were indicated by an increase in $C$ reactive protein 24 hours after the procedure but without any symptoms and demonstrated bubbles around the rectum. The patients were treated conservatively with antibiotics for 7 days. The perforation rate was different according to the experience of the physician with $9.1 \%$ for the beginner (1/11) versus $4.2 \%$ for one expert and $0 \%$ for the others. The two occurrences of bleeding were during the first 24 hours after a gastric ESD procedure. Among them, one patient received a transfusion of two blood units but encountered a spontaneous positive issue without any new endoscopic procedure and one patient required a second look endoscopy for successful endoscopic hemostasis.

The average length of stay for patients who underwent ESD procedures was 2.8 days (SD 1.3, range $2-8$ days).

\section{Discussion}

To the best of our knowledge, the new Nestis Enki $2^{\circledR}$ water jet system is the first device able to inject both saline and macromolecular solutions under high pressure through a single bifunctional catheter. This first experience in humans showed that such injection is effective, feasible, and safe. The cost of this device is not precisely known yet since Nestis ${ }^{\circledR}$ is a very small company looking for support. For the initial experience, the machine was lent to the centers and the cost of the catheter was somewhere between that for Dual Knife ${ }^{\circledR}$ and Hybrid Knife ${ }^{\circledR}$ catheters. Overall, we report a $91.7 \%$ R0 resection rate, no major side effects, only two cases with bubbles around the rectum and without symptoms, and two delayed occurrences of bleeding. This is a 
relatively low perforation rate ( $0 \%$ during the procedures) compared to $18 \%$ in the first European series [9] and a good effectiveness compared to a large series with a $>90 \%$ R0 resection rate $[10,11]$, especially when we consider the lack of experience of one of the six physicians.

This system was used in different parts of the digestive tract including the ascending colon and duodenum without severe adverse events. The number of colonic cases was low since colonic ESD is still controversial in France compared with piecemeal endoscopic mucosal resection (EMR) [12]. The duodenal case was performed before the different reports warning about the perforation risk of such a procedure $[13,14]$ so new evaluation with safer devices such as the Nestis ${ }^{\circledR}$ instrument should be conducted in highly skilled hands.

This system allows a new combination of two important optimizations: viscous solutions with a long lasting cushion effect and powerful water jet injection. These two optimizations have shown their own benefits in terms of safety and effectiveness in previous animal studies $[3,15]$. Furthermore, the combined benefit of this association was previously reported on pig stomach with dissection speed significantly increased by $35 \%$ [6]. It seems to be a safe and easy to use device for beginners since it reduces the number of tool exchanges while retaining the benefits of the injected viscous solutions. It also allows repeated injections immediately before cutting.

Although the best solution is probably hyaluronate, its cost limits its widespread use. If possible, a glycerol mixture seems to be a good option since it has never produced renal failure and since its viscosity is close to that of HES (3.4 mPa.s versus $4.6 \mathrm{mPa} . \mathrm{s}$ ) [6]. In this work, injection was always possible in direct viewing and retroflexion but some difficulties introducing the cartridge into the machine were reported by nurses, and four incidents of tube damage occurred during this preparation time. In some bleeding situations, carbonization appeared at the tip of the device, which can obstruct the hole. Cleaning of the distal tip with a wet compress and frequent repeated injections seem to increase device lifetime.

Our study has some limitations, notably because it is a retrospective work with no comparative group using the standard technique or normal saline injection. The different tumor sites and the different experiences of the operators are also limitations when comparing speeds. Obstruction of the catheter occurred in six cases and represents a limitation of this kind of device but frequent injections and catheter tip cleaning may increase the knife lifetime. Nevertheless, this is the first report of water jet injection with macromolecular solutions in humans without any severe adverse events and with good effectiveness. In the future, such water jets may be used to inject viscous solutions with active components to prevent stenosis, delay bleeding, or to promote healing.

To summarize, the Nestis ${ }^{\circledR}$ Enki 2 system is the first jet injector able to inject viscous macromolecular solutions through a flexible bifunctional catheter even with a retroflexed endoscope. Overall, it is an easy to use and safe device, even in unskilled hands. It might be a good tool to proceed to after pig training. A multicentric prospective study is now scheduled.
Competing interests: Mathieu Pioche received a grant for clinical research from Nestis company.

\section{Institutions}

1 Digestive Disease Department, Hôpital Edouard Herriot, Lyon, France

2 Nestis Clinical Research, Lyon, France

${ }^{3}$ Inserm U1032, LabTau, Lyon, France

${ }^{4}$ Digestive Disease Department, Hôpital Privé Jean Mermoz, Lyon, France

${ }^{5}$ Digestive Disease Department, St-Luc Hospital, Louvain, Belgium

${ }^{6}$ Digestive Disease Department, Institut Paoli Calmette, Marseille, France

${ }^{7}$ Carol Davila University of Medicine and Pharmacy, Fundeni Gastroenterology

Clinic, Bucharest, Romania

${ }^{8}$ Pharmacy, Hôpital Edouard Herriot, Lyon, France

\section{References}

1 Ohkuwa M, Hosokawa K, Boku $N$ et al. New endoscopic treatment for intramucosal gastric tumors using an insulated-tip diathermic knife. Endoscopy 2001; 33: 221 - 226

2 Fujishiro $M$, Yahagi $N$, Kakushima $N$ et al. Endoscopic submucosal dissection of esophageal squamous cell neoplasms. Clin Gastroenterol Hepatol 2006; 4: 688-694

3 Ciocîrlan M, Pioche M, Lepilliez Vet al. The ENKI-2 water-jet system versus Dual Knife for endoscopic submucosal dissection of colorectal lesions: a randomized comparative animal study. Endoscopy 2014; 46: $139-143$

4 Yahagi $N$, Neuhaus $H$, Schumacher $B$ et al. Comparison of standard endoscopic submucosal dissection (ESD) versus an optimized ESD technique for the colon: an animal study. Endoscopy 2009; 41: 340 345

5 Fujishiro M, Yahagi N, Nakamura M et al. Successful outcomes of a novel endoscopic treatment for GI tumors: endoscopic submucosal dissection with a mixture of high-molecular-weight hyaluronic acid, glycerin, and sugar. Gastrointest Endosc 2006; 63: 243-249

6 Pioche $M$, Ciocirlan $M$, Lépilliez $V$ et al. High-pressure jet injection of viscous solutions for endoscopic submucosal dissection: a study on ex vivo pig stomachs. Surg Endosc 2014; 28: 1742 - 1747

7 Pioche M, Mais L, Guillaud $O$ et al. Endoscopic submucosal tunnel dissection for large esophageal neoplastic lesions. Endoscopy 2013; 45: $1032-1034$

8 Japanese Gastric Cancer Association. Japanese gastric cancer treatment guidelines 2010 (ver. 3). Gastric Cancer 2011; 14: 113-123

9 Farhat S, Chaussade S, Ponchon $T$ et al. Endoscopic submucosal dissection in a European setting. A multi-institutional report of a technique in development. Endoscopy 2011; 43: 664-670

10 Chung I-K, Lee JH, Lee S-H et al. Therapeutic outcomes in 1000 cases of endoscopic submucosal dissection for early gastric neoplasms: Korean ESD Study Group multicenter study. Gastrointest Endosc 2009; 69: $1228-1135$

11 Repici A, Hassan C, De Paula Pessoa D et al. Efficacy and safety of endoscopic submucosal dissection for colorectal neoplasia: a systematic review. Endoscopy 2012; 44: 137-150

12 Bourke MJ, Neuhaus $H$. Colorectal endoscopic submucosal dissection: when and by whom? Endoscopy 2014; 46: 677-679

13 Matsumoto S, Miyatani H, Yoshida $Y$. Endoscopic submucosal dissection for duodenal tumors: a single-center experience. Endoscopy 2013; 45: $136-137$

14 Basford PJ, George R, Nixon E et al. Endoscopic resection of sporadic duodenal adenomas: comparison of endoscopic mucosal resection (EMR) with hybrid endoscopic submucosal dissection (ESD) techniques and the risks of late delayed bleeding. Surg Endosc 2014; 28 : $1594-1600$

15 Lepilliez V, Robles-Medranda C, Ciocirlan M et al. Water-jet dissector for endoscopic submucosal dissection in an animal study: outcomes of the continuous and pulsed modes. Surg Endosc 2013; 27: 2921 - 2927 